\title{
Efficiency of sensitizing nano-titania with organic dyes and peroxo complexes
}

\author{
Elena Savinkina $\cdot$ Lubov Obolenskaya $\cdot$ \\ Galina Kuzmicheva
}

Received: 2 January 2014 / Accepted: 12 February 2014/Published online: 5 March 2014

(C) The Author(s) 2014. This article is published with open access at Springerlink.com

\begin{abstract}
A new method of sensitizing titania by treatment of the reaction mixture with Methylene Blue, Methyl Red or hydrogen peroxide is developed; the sensitizer was introduced into the reaction mixture while synthesizing nanosize $\mathrm{TiO}_{2}$ from titanyl sulfate. The samples prepared by this method are compared to the samples prepared by cold impregnation of Methylene Blue, Methyl Red or hydrogen peroxide on titania, pre-synthesized by sulfate method, or commercial Degussa P25 and Hombikat UV100. The samples were characterized by X-ray diffraction; their photocatalytic activity was studied in the model reaction of Methyl Orange decomposition in aqueous solution under UV and visible light. The highest photocatalytic activity under visible light was found for titania, sensitized with titanium peroxo complexes by the new method. It is also active for photodegradation of salicylic acid under visible light.
\end{abstract}

Keywords Nanoparticles - Titania - Sensitization - Dyes · Titanium peroxo complexes

\section{Introduction}

Nanosize titania is the most promising photocatalyst due to efficient photoactivity, high stability, and low toxicity. Titania has been used for energy conversion and photodegradation of many contaminants under UV radiation; its photocatalytic properties in this region are well studied (Hashimoto et al. 2007). To utilize visible light, various

E. Savinkina $(\bowtie) \cdot$ L. Obolenskaya · G. Kuzmicheva Lomonosov State University of Fine Chemical Technology, Vernadskogo 86, Moscow 119571, Russia

e-mail: e.savinkina@mail.ru methods were used to modify $\mathrm{TiO}_{2}$, including doping and photosensitization (Carp et al. 2004; Banerjee 2011; Viswanathan and Krishnamurthy 2012).

Inorganic sensitizers, organic dyes, and coordination metal complexes are very effective sensitizers that were studied mostly (Fujishima and Rao 1998; Sauvé et al. 2000; Pei and Luan 2012; Zhou et al. 2012). Epling and Lin (2002) investigated photo-assisted bleaching of 15 dyes utilizing $\mathrm{TiO}_{2}$ and visible light; good rate for Methylene Blue (MeB) decomposition can be explained by titania sensitization; the MeB photobleaching rates were: anatase $>$ amorphous titania $>$ rutile. Hussein and Alkhateeb (2007) sensitized titanium dioxide by impregnation of organic dyes on the commercial photocatalyst Degussa P25. The photo-oxidation of benzyl alcohol was found to be in the sequence: riboflavin $>$ Safranin $\mathrm{O}>$ naked $\mathrm{TiO}_{2}>$ Methyl Red $(\mathrm{MeR})>$ Eosin $\mathrm{B}>$ Methylene Blue. Dye sensitization is usually accompanied by such problems as dye desorption and backward transfer (recombination) during the photoreaction (Zhang et al. 2012). Houas et al. (2001) presented a detailed reaction mechanism from the initial step of adsorption involving the cationic functional group of MeB molecule, which is probably adsorbed perpendicularly to the surface down, to the final products $\left(\mathrm{CO}_{2}, \mathrm{SO}_{4}{ }^{2-}, \mathrm{NH}_{4}{ }^{+}\right.$, and $\left.\mathrm{NO}_{3}{ }^{-}\right)$.

Titanium is known to form yellow-colored peroxo complexes. Zou et al. (2009) prepared $\mathrm{H}_{2} \mathrm{O}_{2}$-sensitized sulfated titania nanoparticles with a response to visible light by introduction of hydrogen peroxide into a photoreactor containing titania and Methyl Orange $(\mathrm{MeO})$; degradation of $\mathrm{MeO}$ was completed in $4 \mathrm{~h}$. A sol-gel technique using the peroxo titanic acid sol as a precursor for fabrication of the $\mathrm{TiO}_{2}$ photocatalytic films is reported; the peroxo titanic acid sol was synthesized from titanyl sulfate (Ge and $\mathrm{Xu}$ 2007) or titanium(IV) tetrabutoxide 
(Sonawane et al. 2003) and $\mathrm{H}_{2} \mathrm{O}_{2}$ solution. The films showed high photocatalytic activity under UV light; however, no experiments using visible light were carried out in these works. Karuppuchamy and Jeong (2006) prepared amorphous powder of titanium peroxo complex from Ti$\mathrm{OSO}_{4}$ and $\mathrm{H}_{2} \mathrm{O}_{2}$ at room temperature, which was then converted to anatase by heat treating at $300{ }^{\circ} \mathrm{C}$; photocatalytic activity of the product was not studied.

The purpose of the work was to prepare sensitized photocatalysts on the basis of titanium dioxide (using organic and inorganic compounds) by various methods and studying their photocatalytic activity in the model reactions of $\mathrm{MeO}$ and salicylic acid degradation.

\section{Materials and methods}

\section{Synthesis}

Nano-anatase (A) was prepared by hydrolysis of $\mathrm{TiOSO}_{4}$ by the reported method (Obolenskaya et al. 2012a, b) with the use of solvated titanyl sulfate (Aldrich) as an initial reagent.

Sensitization of titanium dioxide with Methylene Blue (3,7-bis(dimethylamino)phenothiazin-5-ium chloride), Methyl Red (2-(N,N-dimethyl-4-aminophenyl)azobenzenecarboxylic acid), or hydrogen peroxide was performed by two different methods (Table 1).

Method 1 (samples 1-9) is based on the cold impregnation of a sensitizer on $\mathrm{TiO}_{2}$ in a similar manner as described by Carp et al. (2004). Titania powder $(0.25 \mathrm{~g})$ was dispersed in $50 \mathrm{ml}$ of $7 \times 10^{-5} \mathrm{M}$ solution of Methylene Blue $\left(\mathrm{TiO}_{2}: \mathrm{MeB}=250: 1\right), 7 \times 10^{-5} \mathrm{M}$ solution of Methyl Red $\left(\mathrm{TiO}_{2}: \mathrm{MeR}=250: 1\right)$, or $10 \mathrm{M}$ solution of $\mathrm{H}_{2} \mathrm{O}_{2}\left(\mathrm{TiO}_{2}: \mathrm{H}_{2} \mathrm{O}_{2}=1: 160\right)$, stirred for 40 min with a magnetic stirrer at room temperature, filtered off, washed with water and acetone, dried at room temperature and ground.

The method was used for sensitizing anatase (A), prepared by hydrolysis of titanyl sulfate, commercial Aeroxide Degussa (Evonik) P25, prepared by pyrolysis of titanium tetrachloride, and Hombikat UV100, prepared by pyrolysis of titanyl sulfate, with $\mathrm{MeB}, \mathrm{MeR}$, and $\mathrm{H}_{2} \mathrm{O}_{2}$ (see Table 1 for sample numbering).

Method 2 (samples 10-12) is based on adding a sensitizing agent into the reaction solution while synthesizing
$\mathrm{TiO}_{2}$ from $\mathrm{TiOSO}_{4}$ (Obolenskaya et al. 2012a, b). Solvated titanyl sulfate (Aldrich) was mixed with water (1:5.44) and heated up to $87^{\circ} \mathrm{C}$ till complete dissolution. The reaction mixture was stirred at $88-90{ }^{\circ} \mathrm{C}$ for $1.5 \mathrm{~min}$ and quickly cooled down to $0{ }^{\circ} \mathrm{C}$. Then aqueous solutions of $\mathrm{KCl}$ (final concentration $3.3 \mathrm{~mol} / \mathrm{L}$ ) and $\mathrm{MeB}, \mathrm{MeR}$, or $\mathrm{H}_{2} \mathrm{O}_{2}$ were added, the precipitate was filtered off, washed with water, aqueous solution of $\mathrm{Na}_{2} \mathrm{SO}_{3}$ (to remove unreacted $\mathrm{H}_{2} \mathrm{O}_{2}$ ) and acetone, and dried at $90-98{ }^{\circ} \mathrm{C}$.

It is noteworthy that sensitization by method 2 is inapplicable to Degussa P25 and Hombikat UV100, since they cannot be synthesized in solution.

Titania sensitized with $\mathrm{H}_{2} \mathrm{O}_{2}, \mathrm{MeB}$, and MeR is stable at least for 2 months (6 months in a refrigerator), 1 year, and 6 months, respectively.

\section{Characterization}

All the samples were characterized by X-ray diffraction (XRD) patterns, which were recorded with sample rotation on an HZG-4 (Ni filter) diffractometer: $\mathrm{Cu} K_{\alpha}$ radiation in the diffracted beam, stepwise mode (counting time $10 \mathrm{~s}$, a step of $0.02^{\circ}$ ). Qualitative XRD phase analyses were carried out using JCPDS PDF-2 and literature data. The sizes of coherent scattering regions $(L, \AA$ ) were evaluated using the Scherrer formula:

$L=0.9 \lambda / \beta \cos \theta$,

where $\beta$ is the measured integral breadth of the peak $\left(2 \theta \sim 25^{\circ}\right)$.

The microstructure of the samples was studied by scanning electron microscopy with the use of a JSM 7500F electron microscope in the secondary electron mode.

The nitrogen sorption capacity at $-196{ }^{\circ} \mathrm{C}$ for the samples was measured volumetrically within the range of equilibrium relative nitrogen pressures of $0.01-0.99$ with a Micromeritics ASAP 2020 gas analyzer (GSI no. 46147-10). The specific surface area and pore volume of samples were determined by the Brunauer-Emmett-Teller (BET) method and by comparative method from the adsorption isotherm in the region of equilibrium relative pressure of nitrogen $0.05-0.35$ and $0.4-0.8$, respectively.

The average sizes of particles were calculated according to formula:

$N=K p(\rho A)$,

Table 1 Sample numbering/rate constants $\left(k, \min ^{-1}\right)$ for $\mathrm{MeO}$ decomposition under visible light

\begin{tabular}{lllll}
\hline Sensitizer & Method 1 anatase $(\mathrm{A})$ & Method 1 Degussa P25 & Method 1 Hombikat UV100 & Method 2 \\
\hline $\mathrm{MeB}$ & Sample 1 (A-MeB)/0.0022 & Sample 4 (P25-MeB)/0.0019 & Sample 7 (UV100-MeB)/0.0014 & Sample 10 (MeB-TiO $) / 0.0082$ \\
$\mathrm{MeR}$ & Sample 2 (A-MeR)/0.0014 & Sample 5 $(\mathrm{P} 25-\mathrm{MeR}) / 0.0006$ & Sample 8 $(\mathrm{UV} 100-\mathrm{MeR}) / 0.0009$ & Sample 11 $\left.(\mathrm{MeR}-\mathrm{TiO})_{2}\right) / 0.0064$ \\
$\mathrm{H}_{2} \mathrm{O}_{2}$ & Sample 3 $\left(\mathrm{A}-\mathrm{H}_{2} \mathrm{O}_{2}\right) / 0.0047$ & Sample 6 $\left(\mathrm{P} 25-\mathrm{H}_{2} \mathrm{O}_{2}\right) / 0.0012$ & Sample 9 $\left(\mathrm{UV} 100-\mathrm{H}_{2} \mathrm{O}_{2}\right) / 0.0035$ & Sample 12 $\left(\mathrm{H}_{2} \mathrm{O}_{2}-\mathrm{TiO}_{2}\right) / 0.0470$ \\
\hline
\end{tabular}


where $N$ is the average size of the particles; $K \mathrm{p}$ is the shape factor of the particles ( 6 for cubes and spheres, 4 for prisms and round rods, 2 for plates); $\rho$ is the density of the material $\left(\rho=3.84 \mathrm{~g} / \mathrm{cm}^{3}\right)$; and $A$ is the specific surface area of the material.

Microphotos were made with a Levenhuk camera installed on a Levenhuk D2L microscope. The average sizes of aggregates were estimated by measuring ten randomly chosen aggregates and calculating simple mean value.

Electronic absorption spectra were recorded with an Aquilon CF 103 UV/vis spectrophotometer. IR spectra were recorded with an Infralum FT-02 (Nujol mulls) spectrometer at room temperature.

\section{Photocatalysis}

Properties of the samples were studied in the model reactions of photocatalytic degradation of organic dye Methyl Orange (4-dimethylaminoazobenzene-4'-sulfonic acid sodium salt) or salicylic acid under UV (DRT-125 mercury lamp, $\lambda=250-400 \mathrm{~nm}$ ) and visible irradiation (OSRAM halogen lamp with a filter, $\lambda>450 \mathrm{~nm}$, nominal power $40-250 \mathrm{~W}$ ) in a photoreactor system with continuous stirring. The depth and surface of the solution were $0.04 \mathrm{~m}$ and $0.09 \mathrm{~m}^{2}$, respectively. In a typical experiment, a sample was put into aqueous solution of the $\mathrm{MeO}$ dye or salicylic acid; the initial $\mathrm{MeO}$ dye or salicylic acid concentration and the amount of $\mathrm{TiO}_{2}$ were set at $0.05,0.4 \mathrm{mmol} / \mathrm{L}$ and $0.4 \mathrm{~g} / \mathrm{L}$, respectively; $\mathrm{pH} \sim 5$ for all samples excluding nontreated anatase $(\mathrm{A})(\mathrm{pH} \sim 3)$. Degradation was monitored by measuring intensity of the peak at $\lambda=450-470 \mathrm{~nm}$ at $\mathrm{pH} \sim 3$ or $495-515 \mathrm{~nm}$ at $\mathrm{pH} \sim 5$ for the $\mathrm{MeO}$ dye $(\mathrm{MeO}$ is an acid-base indicator, and the position of the absorption band depends on $\mathrm{pH}$ ) and at $\lambda=280 \mathrm{~nm}$ for salicylic acid.

The photocatalytic destruction of the $\mathrm{MeO}$ dye and salicylic acid can be described by the first-order kinetic model, $\ln \left(c_{0} / c\right)=k t$, where $c_{0}$ is the initial concentration and $c$ is the concentration at time $t$ (Brown and Darwent 1984). Uncertainties in determining rate constants were $\sim 10 \%$.

\section{Results}

\section{Characterization of samples}

Figures 1 and 2 show the X-ray diffraction patterns of the samples, containing initial titania, which were used for preparing photocatalysts by method 1 , and samples 10-12, prepared by method 2 , respectively.

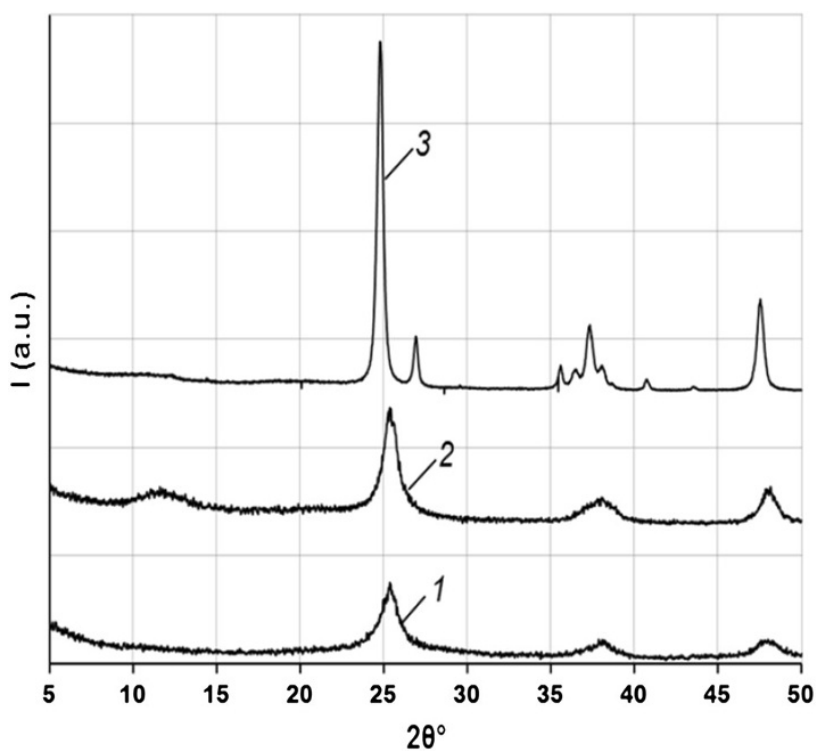

Fig. 1 XRD patterns: 1-self-made anatase (A), 2-Hombikat UV100 (UV100), 3-Aeroxide Degussa (Evonik) P25 (P25)

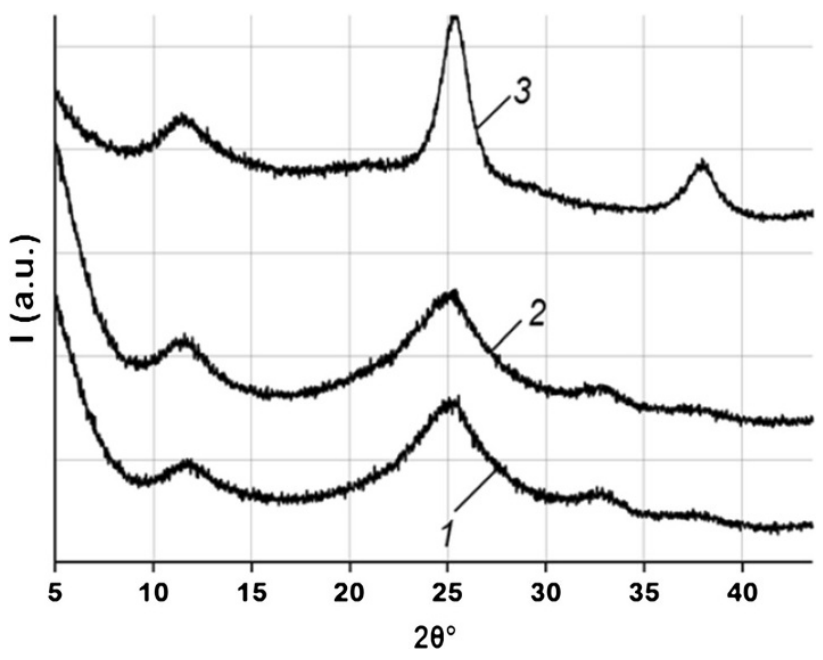

Fig. 2 XRD patterns of titania, sensitized by method 2 with MeB (1), MeR (2), and $\mathrm{H}_{2} \mathrm{O}_{2}$ (3)

Samples of $\mathrm{TiO}_{2}$, prepared by the sulfate method, contain only one phase, anatase (Fig. 1; Table 2). Degussa P25 contains nano-anatase and nano-rutile in the $\sim 85$ : 15 ratio (Fig. 1; Table 2). Hombikat UV100 (Fig. 1) contains, along with nano-anatase, a phase with a characteristic diffraction reflection at $2 \theta \sim 12^{\circ}$. According to Dadachov (2006), this peak belongs to hydrous titania $\mathrm{TiO}_{2-x}$ $(\mathrm{OH})_{2 x} y \mathrm{H}_{2} \mathrm{O}$, where $y$ is about 1 . Therefore, Hombikat UV100 contains $\sim 9 \%$ of hydrous titania (Table 2). According to technical information, Degussa P25 and Hombikat UV100 consist of nanoparticle $\sim 20$ and $<10 \mathrm{~nm}$ in size, respectively. Our measurements with the use of SEM and comparative method based on nitrogen 
Table 2 Composition (\%) and coherent scattering regions $(L, \AA)$ for titania samples

\begin{tabular}{lllll}
\hline Sample & Anatase $/ L$ & Rutile/L & $\eta-\mathrm{TiO}_{2} / L$ & $\begin{array}{l}\text { Hydrous } \\
\text { titania }\end{array}$ \\
\hline Anatase (A) & $100 / 75(4)$ & - & - & - \\
Degussa P25 & $85 / 178(9)$ & $15 / 255(13)$ & - & - \\
Hombikat UV100 & $91 / 82(4)$ & - & - & 9 \\
$\mathbf{1}(\mathrm{A}-\mathrm{MeB})$ & $99 / 70(3)$ & - & - & 1 \\
$\mathbf{2}(\mathrm{A}-\mathrm{MeR})$ & $58 / 80(4)$ & - & - & 42 \\
$\mathbf{3}\left(\mathrm{A}-\mathrm{H}_{2} \mathrm{O}_{2}\right)$ & $87 / 70(3)$ & - & - & 13 \\
$\mathbf{4}(\mathrm{P} 25-\mathrm{MeB})$ & $85 / 170(8)$ & $13 / 170(13)$ & - & 2 \\
$\mathbf{5}(\mathrm{P} 25-\mathrm{MeR})$ & $53 / 185(9)$ & $9 / 320(16)$ & - & 38 \\
$\mathbf{6}\left(\mathrm{P} 25-\mathrm{H}_{2} \mathrm{O}_{2}\right)$ & $54 / 180(9)$ & $8 / 245(12)$ & - & 38 \\
$\mathbf{7}(\mathrm{UV} 100-\mathrm{MeB})$ & $54 / 90(5)$ & - & - & 46 \\
$\mathbf{8}(\mathrm{UV} 100-\mathrm{MeR})$ & $99 / 80(4)$ & - & - & 1 \\
$\mathbf{9}\left(\mathrm{UV} 100-\mathrm{H}_{2} \mathrm{O}_{2}\right)$ & $69 / 85(4)$ & - & - & 31 \\
$\mathbf{1 0}(\mathrm{MeB}-\mathrm{TiO} 2)$ & - & - & $85 / 50(2)$ & 15 \\
$\mathbf{1 1}(\mathrm{MeR}-\mathrm{TiO} 2)$ & - & - & $83 / 40(2)$ & 17 \\
$\mathbf{1 2}\left(\mathrm{H}_{2} \mathrm{O}_{2}-\mathrm{TiO} 2\right)$ & $81 / 50(2)$ & - & - & 19 \\
\hline
\end{tabular}

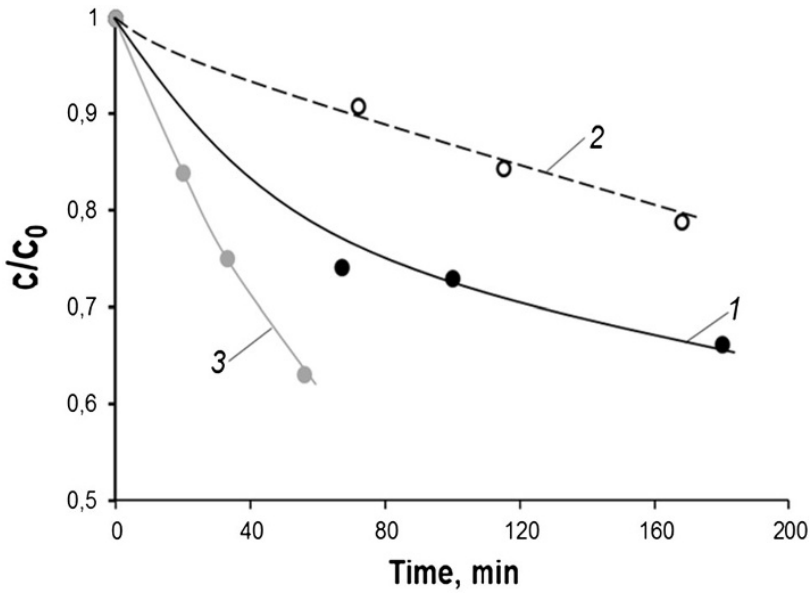

Fig. 3 Degree of decolorization of Methyl Orange under visible light in the presence of MeB-sensitized titania: 1-sample 1 (A-MeB), 2sample 7 (UV100-MeB), 3-sample $10\left(\mathrm{MeB}-\mathrm{TiO}_{2}\right)$

sorption capacity showed the sizes of the particles 28-30 nm for Degussa P25 and $12 \mathrm{~nm}$ for Hombikat UV100. Specific surface area measured by the comparative method was $53-54 \mathrm{~m}^{2} / \mathrm{g}$ for Degussa P25 and $>123 \mathrm{~m}^{2} / \mathrm{g}$ for Hombikat UV100; volume of micro pores $(<300 \mathrm{~nm})$ was 0.163 and $0.344 \mathrm{~cm}^{3} / \mathrm{g}$, respectively.

Impregnation with organic dyes and $\mathrm{H}_{2} \mathrm{O}_{2}$ by method 1 changes titania composition. Since modification of the titania samples was carried out in aqueous media, all modified samples contain hydrous titania (Table 2). Its quantity is small (1-2\%), when self-made anatase (A) and Degussa P25 are modified with $\mathrm{MeB}$ and large (up to

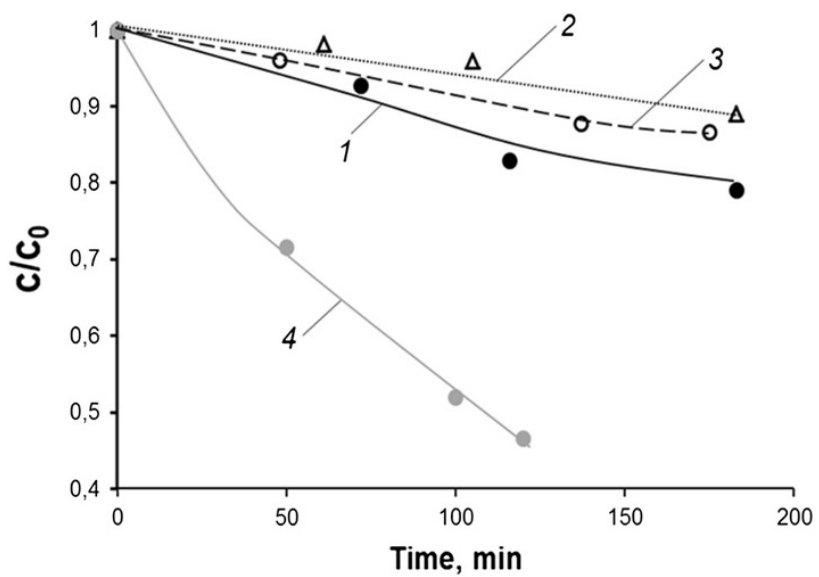

Fig. 4 Degree of decolorization of Methyl Orange under visible light in the presence of MeR-sensitized titania: 1-sample 2 (A-MeR), 2sample 5 (P25-MeR), 3-sample 8 (UV100-MeR), 4-sample 11 $\left(\mathrm{MeR}-\mathrm{TiO}_{2}\right)$

$42 \%$ ), when the same initial titania samples are treated with $\mathrm{MeR}$ and $\mathrm{H}_{2} \mathrm{O}_{2}$. Content of hydrous titania in Hombikat UV100 decreases down to $1 \%$ on treatment with MeR and increases up to 46 and $31 \%$ on treatment with $\mathrm{MeB}$ and $\mathrm{H}_{2} \mathrm{O}_{2}$, respectively (Table 2). The anatase:rutile ratio in the samples based on Degussa P25 and sizes of coherent scattering regions in all samples prepared by method 1 do not vary significantly (Table 2).

Preparing sensitized titania by the new method for sensitizing tinania-method 2-resulted in formation of the samples containing $\eta-\mathrm{TiO}_{2}(83-85 \%)$ and hydrous anatase (15-17\%) when using organic dyes, and containing anatase $(81 \%)$ and hydrous anatase $(19 \%)$ when using $\mathrm{H}_{2} \mathrm{O}_{2}$ (Fig. 2; Table 2).

Photocatalytic properties of sensitized titania under visible light

The MeB- and MeR-sensitized titania (A) samples, prepared by method 1 (samples $\mathbf{1}$ and $\mathbf{2}$, respectively), show no significant preference as compared to the commercial photocatalysts Degussa P25 (samples 4 and 5, respectively) and Hombikat UV100 (samples $\mathbf{7}$ and $\mathbf{8}$, respectively) (Table 1; Figs. 3, 4). The degree of $\mathrm{MeO}$ decolorization in the presence of $\mathrm{P} 25-\mathrm{MeB}$ sample is nonmonotonous; an increase of the dye concentration at 130-170 min can be caused by washing the pre-adsorbed dye off the surface of Degussa P25.

Sensitization of titania by method 2, developed in this work, with MeB (sample 10) and MeR (sample 11) results in higher photocatalytic activity (Table 1; Figs. 3, 4, curves 4); see "Discussion". The best result for dye sensitizing was achieved with the use of MeB (sample 10). 


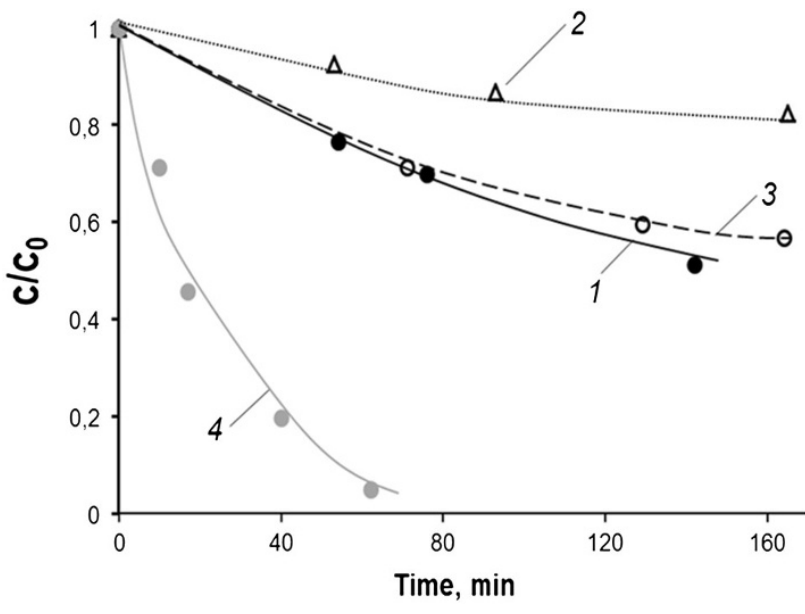

Fig. 5 Degree of decolorization of Methyl Orange under visible light in the presence of $\mathrm{H}_{2} \mathrm{O}_{2}$-sensitized titania: 1-sample $3\left(\mathrm{~A}-\mathrm{H}_{2} \mathrm{O}_{2}\right)$, 2-sample $6\left(\mathrm{P} 25-\mathrm{H}_{2} \mathrm{O}_{2}\right), 3$-sample $9\left(\mathrm{UV} 100-\mathrm{H}_{2} \mathrm{O}_{2}\right), 4$-sample 12 $\left(\mathrm{H}_{2} \mathrm{O}_{2}-\mathrm{TiO} 2\right)$

After treatment with hydrogen peroxide (method 1), Degussa P25 turned pale yellow; the yellow color for A- $\mathrm{H}_{2} \mathrm{O}_{2}$ and UV100- $\mathrm{H}_{2} \mathrm{O}_{2}$ was more intensive. However, the samples on the basis of Hombikat UV100 decolorize on storage (even in darkness). The rate of the photoreaction was higher for $\mathrm{A}-\mathrm{H}_{2} \mathrm{O}_{2}$ (sample 3) and UV100- $\mathrm{H}_{2} \mathrm{O}_{2}$ (sample 9) and lower for $\mathrm{P} 25-\mathrm{H}_{2} \mathrm{O}_{2}$ (sample 6) than for the corresponding dye-sensitized samples (Table 1; Fig. 5, curves 1-3). However, it was much lower than for samples 10 and 11, prepared by sensitizing titania with dyes by the new method, developed in this work (method 2$)$.

The best visible light photocatalyst, $\mathrm{H}_{2} \mathrm{O}_{2}-\mathrm{TiO}_{2}$ (sample 12) was prepared by treatment of the reaction mixture with $\mathrm{H}_{2} \mathrm{O}_{2}$ while synthesizing titanium dioxide from titanyl sulfate (method 2). As shown in Fig. 5 (curve 4) complete decomposition of $\mathrm{MeO}$ in the presence of $\mathrm{H}_{2} \mathrm{O}_{2}-\mathrm{TiO}_{2}$ under visible light takes $60-80 \mathrm{~min}$, which is better than for the samples sensitized with organic dyes (Figs. 3, 4). It is noteworthy that the sample contains no free or adsorbed $\mathrm{H}_{2} \mathrm{O}_{2}$ since it was completely removed during preparing sensitized $\mathrm{TiO}_{2}$. All peroxo groups are strongly coordinated by titanium atoms. Therefore, in contrast to Zou et al. (2009), the effect of destruction $\mathrm{MeO}$ with $\mathrm{H}_{2} \mathrm{O}_{2}$ is excluded.

The results of studying photocatalytic activity of sensitized titania under visible light and dependence of the rate constants on the lamp power are summarized in Figs. 6 and 7. For all the samples, increase of the lamp power first leads to increase of the reaction rate. However, for the samples prepared by method 2 , the reaction rate is almost independent of the lamp power $>60 \mathrm{~W}$; this may be caused by stronger electron-hole pair recombination as compared to the samples prepared by method 1 .

The $\mathrm{H}_{2} \mathrm{O}_{2}-\mathrm{TiO}_{2}$ (sample 12) photocatalytic activity exceeds the activity of the earlier reported visible light-responsible

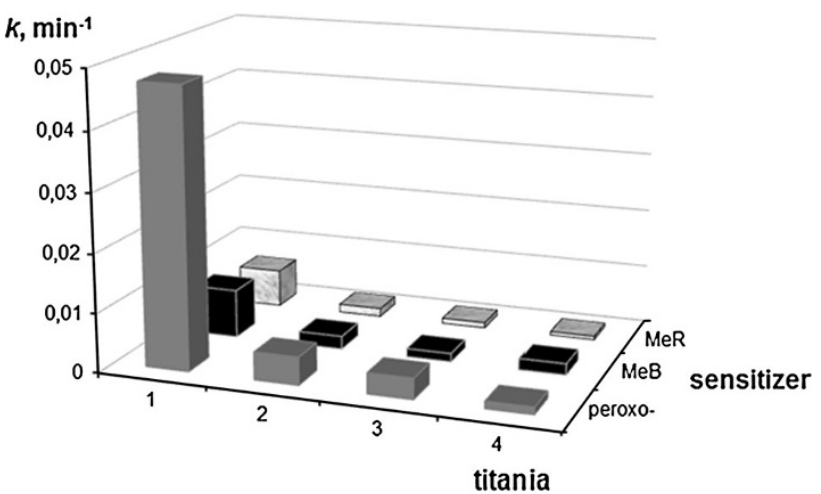

Fig. 6 First-order kinetics rate constant $(k)$ of Methyl Orange decomposition under visible light in the presence of titania sensitized by method 2 (1) and anatase (A) (2), Hombikat UV100 (3), and Degussa (Evonik) P25 (4) sensitized by method 1

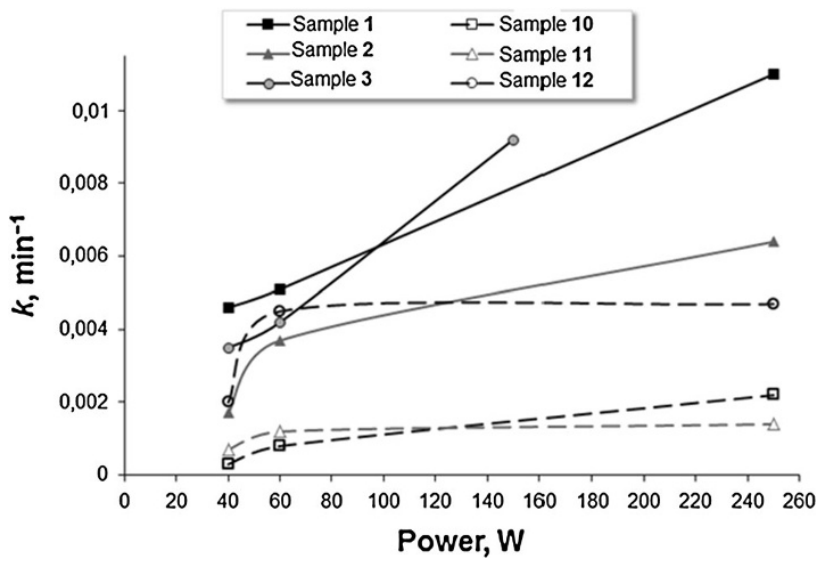

Fig. 7 Rate constant vs. halogen lamp power for sensitized titania: A-MeB, A-MeR, A- $\mathrm{H}_{2} \mathrm{O}_{2}$ (samples 1-3, respectively) and $\mathrm{MeB}-$ $\mathrm{TiO}_{2}, \mathrm{MeR}-\mathrm{TiO}_{2}, \mathrm{H}_{2} \mathrm{O}_{2}-\mathrm{TiO}_{2}$ (samples 10-12, respectively)

photocatalysts. The best previous results were the following: complete decomposition of $\mathrm{MeO}$ catalyzed by N/Ag- and S/Ag-doped titania took 1.5 and $4 \mathrm{~h}$, respectively (Varma et al. 2011). Our photocatalyst $\left(\mathrm{H}_{2} \mathrm{O}_{2}-\mathrm{TiO}_{2}\right)$ decreases the degradation time down to $1 \mathrm{~h}$, although we used less powerful lamp along with lower catalyst content and $\mathrm{MeO}$ concentration.

Photocatalytic properties of sensitized titania under UV light

Sensitization should not affect photocatalytic properties of titania under UV radiation; however, they can be changed due to modification of the surface. That is why we compared photocatalytic activity of pure titania (self-made titania, Degussa P25, and Hombikat UV100) and the samples treated with $\mathrm{MeB}, \mathrm{MeR}$, and $\mathrm{H}_{2} \mathrm{O}_{2}$. In addition, photocatalytic activity of initial titania, pre-dispersed in water by stirring for $40 \mathrm{~min}$, was also examined. 
The results are summarized in Table 3 and Fig. 8.

\section{Discussion}

The samples of self-made titania, sensitized by treatment with organic dyes and hydrogen peroxide, are inferior to commercial titania in photocatalytic activity under UV radiation (Fig. 8). However under visible light, their

Table 3 Rate constants $\left(k, \mathrm{~min}^{-1}\right)$ for $\mathrm{MeO}$ decomposition under UV light in the presence of pure and modified titania (samples 1-9)

\begin{tabular}{llll}
\hline Treatment with & Anatase (A) & Degussa P25 & Hombikat UV100 \\
\hline- & 0.039 & 0.068 & 0.084 \\
$\mathrm{H}_{2} \mathrm{O}$ & 0.036 & 0.052 & 0.084 \\
$\mathrm{MeB}$ & $\mathbf{1} / 0.040$ & $\mathbf{4} / 0.065$ & $\mathbf{7 / 0 . 0 7 9}$ \\
$\mathrm{MeR}$ & $\mathbf{2} / 0.001$ & $\mathbf{5} / 0.074$ & $\mathbf{8} / 0.043$ \\
$\mathrm{H}_{2} \mathrm{O}_{2}$ & $\mathbf{3} / 0.088$ & $\mathbf{6} / 0.069$ & $\mathbf{9 / 0 . 0 9 0}$ \\
\hline
\end{tabular}

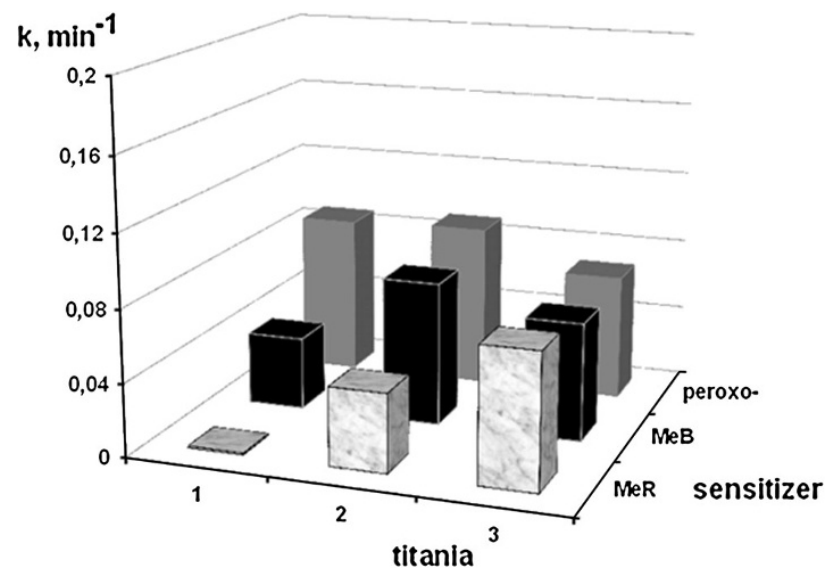

Fig. 8 First-order kinetics rate constant $(k)$ of Methyl Orange decomposition under UV light in the presence of titania sensitized by method 1: 1-anatase (A), 2-Hombikat UV100, 3-Degussa P25 photocatalytic activity is comparable (for self-made titania sensitized by method 1) to Degussa P25 and Hombikat UV100 or much higher (for titania sensitized by method 2) (Fig. 6). Therefore, we can conclude that sensitization with $\mathrm{MeB}, \mathrm{MeR}$, and $\mathrm{H}_{2} \mathrm{O}_{2}$ is more effective for anatase, prepared by hydrolysis, than for anatase and/or rutile, prepared by pyrolysis.

The best results were achieved for the samples, prepared by the novel method 2, since sensitizers can incorporate into the surface of forming nano-titania. When nano-titania is already formed (method 1), the incorporation becomes more difficult. This is supported by IR spectroscopy. IR spectra of all the samples contain bands of titania (Table 4). However, the bands of sensitizers are observable only in the spectra of the samples prepared by method 2 .

Earlier, it was suggested that photocatalytic destruction of organic matter on $\mathrm{TiO}_{2}$ films proceeds partly through formation of hydroxyl radicals which are formed from surface hydroxyl groups created by interactions between adsorbed water and vacancies on the $\mathrm{TiO}_{2}$ surface; a correlation between the amount of $\mathrm{OH}$ groups on the surface of the different $\mathrm{TiO}_{2}$ films and the photocatalytic activity was found (Simonsen et al. 2008). It was shown that formation of more hydroxyl groups in the surface of $\mathrm{TiO}_{2}$ results in higher photocatalytic activity when treating hydrothermally the $\mathrm{TiO}_{2}$ powder (P25) in pure water at $150{ }^{\circ} \mathrm{C}$ for different times (Jiaguo et al. 2006).

Although activity for Degussa P25 photocatalyst is often higher than for Hombikat UV 100 (Colón et al. 2001), in this work, Degussa P25 is more active only when it is sensitized with MeR under UV radiation and with MeB under visible light. The efficiency of various sensitizers in the photoreaction under visible light increases in the sequence $\mathrm{MeR}-\mathrm{MeB}-\mathrm{H}_{2} \mathrm{O}_{2}$ for self-made titania (A).

The mechanisms of sorption for $\mathrm{H}_{2} \mathrm{O}_{2}$ and organic dyes are fundamentally different. Hydrogen peroxide reacts chemically with titania surface producing colored peroxo titanium complexes (Kubota et al. 1995), while MeR

Table 4 IR spectra of the samples

\begin{tabular}{|c|c|c|c|c|c|c|}
\hline \multirow[t]{2}{*}{ Assignment } & \multicolumn{3}{|l|}{ Method 1} & \multicolumn{3}{|l|}{ Method 2} \\
\hline & $\begin{array}{l}\text { A-MeB } \\
\text { sample } 1\end{array}$ & $\begin{array}{l}\text { A-MeR } \\
\text { sample } 2\end{array}$ & $\begin{array}{l}\mathrm{A}-\mathrm{H}_{2} \mathrm{O}_{2} \\
\text { sample 3 }\end{array}$ & $\begin{array}{l}\mathrm{MeB}-\mathrm{TiO}_{2} \\
\text { sample 10 }\end{array}$ & $\begin{array}{l}\mathrm{MeR}-\mathrm{TiO}_{2} \\
\text { sample 11 }\end{array}$ & $\begin{array}{l}\mathrm{H}_{2} \mathrm{O}_{2}-\mathrm{TiO}_{2} \\
\text { sample 12 }\end{array}$ \\
\hline $\begin{array}{c}\delta(\mathrm{Ti}-\mathrm{O}-\mathrm{Ti}) \\
\delta(\mathrm{Ti}-\mathrm{O}-\mathrm{O})\end{array}$ & 721 & 722 & $721 ; 882,986$ & 721 & 721 & $727 ; 798,892,996$ \\
\hline$\delta(\mathrm{Ti}-\mathrm{O}-\mathrm{H})$ & $1,062,1,168$ & $1,065,1,122-1,139$ & $1,041+1,074,1,136$ & $1,116,1,147$ & $1,050,1,121$ & $1,065,1,119$ \\
\hline$\delta(\mathrm{H}-\mathrm{O}-\mathrm{H})$ & $1,599,1,622$ & $1,618-1,643$ & 1,640 & $1,627-1,634$ & $1,616-1,655$ & 1,633 \\
\hline$v(\mathrm{H}-\mathrm{OH})$ & $3,141-3,263$ & $3,101-3,349$ & $3,178-3,219,3,328-3,420$ & $3,131-3,403$ & $3,210-3,391$ & $3,109-3,456$ \\
\hline $\begin{array}{c}\delta(\mathrm{Ti}-\mathrm{O}-\mathrm{Ti}) \\
\delta(\mathrm{Ti}-\mathrm{O}-\mathrm{O})\end{array}$ & 721 & 722 & $721 ; 882,986$ & 721 & 721 & $727 ; 798,892,996$ \\
\hline$\delta(\mathrm{Ti}-\mathrm{O}-\mathrm{H})$ & $1,062,1,168$ & $1,065,1,122-1,139$ & $1,041+1,074,1,136$ & $1,116,1,147$ & $1,050,1,121$ & $1,065,1,119$ \\
\hline
\end{tabular}



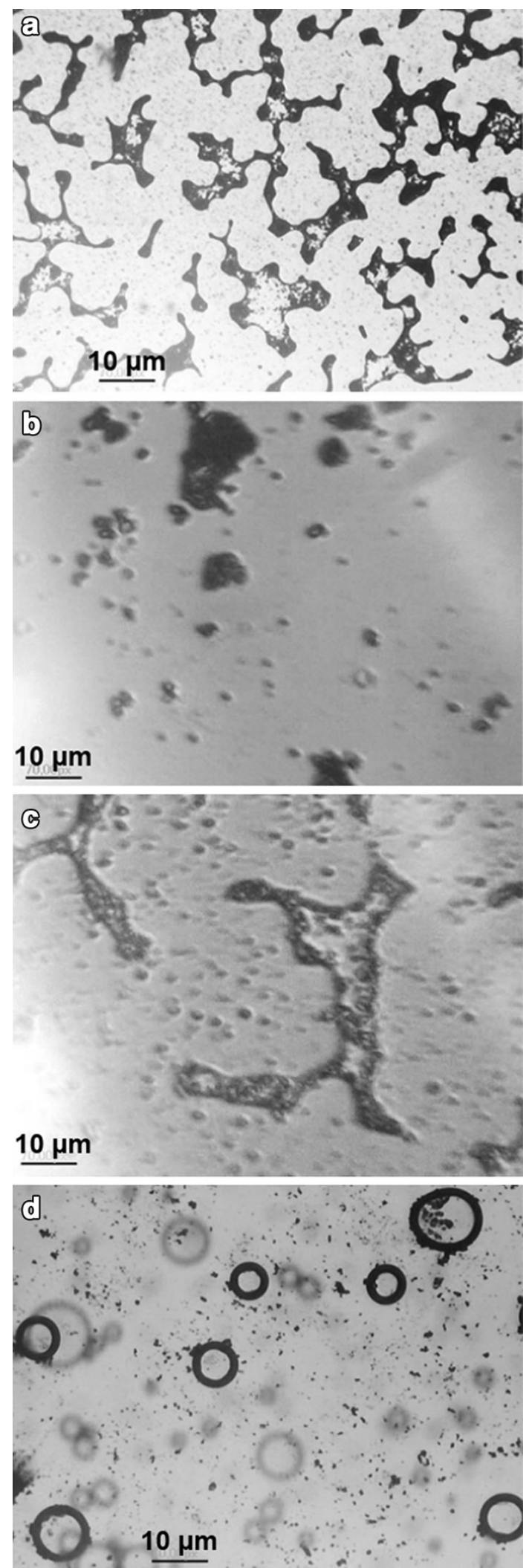

Fig. 9 Microphotos of anatase (A) dispersed in water (a), $6.6 \times 10^{-4} \mathrm{M} \mathrm{MeR}(\mathbf{b}), 6.6 \times 10^{-4} \mathrm{M} \mathrm{MeB}(\mathbf{c})$, and $10 \mathrm{M} \mathrm{H}_{2} \mathrm{O}_{2}$ (d). Circles in photo (d) are oxygen bubbles eliminating from concentrated $\mathrm{H}_{2} \mathrm{O}_{2}$
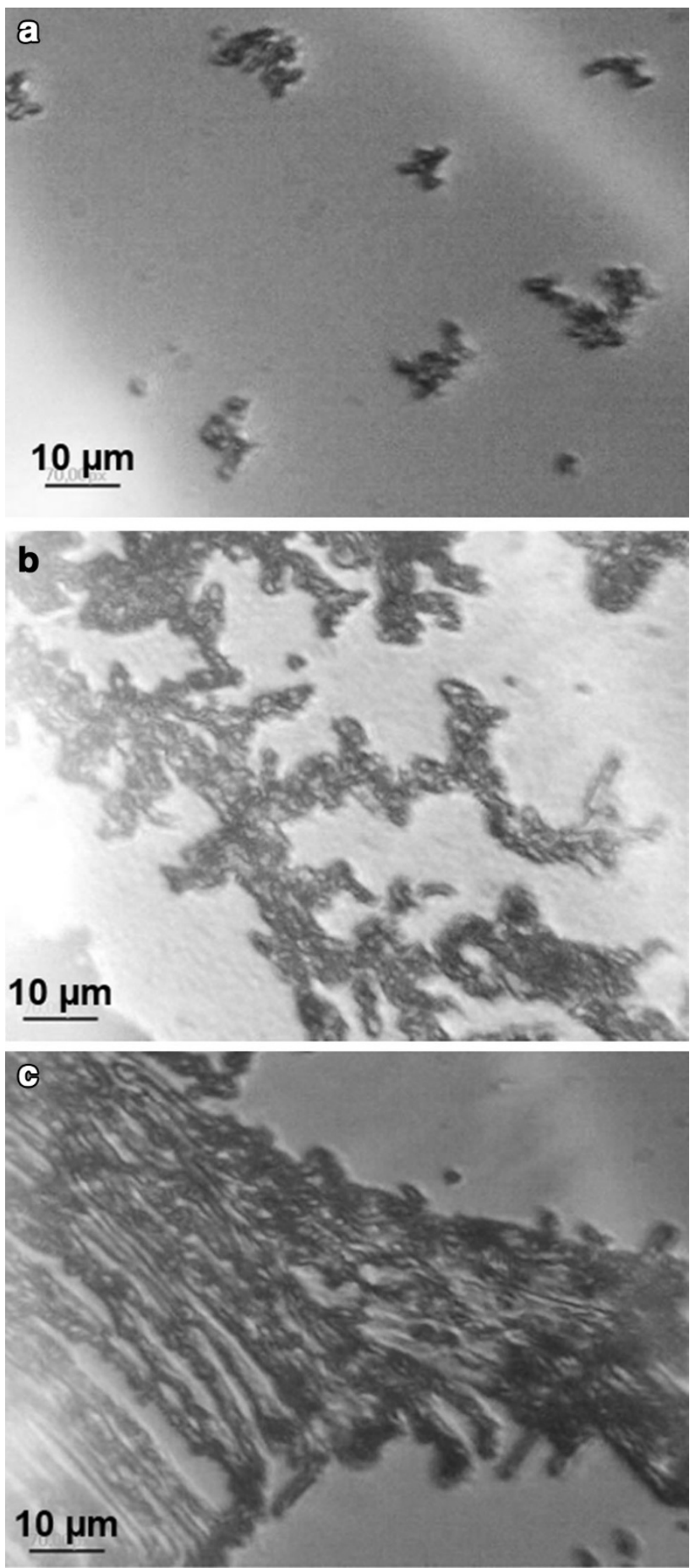

Fig. 10 Microphotos of $\mathrm{TiO}_{2}$ sol mixed with $10 \mathrm{M} \mathrm{KCl}$ and $6.6 \times 10^{-4} \mathrm{M} \mathrm{MeR}(\mathbf{a}), 6.6 \times 10^{-4} \mathrm{M} \mathrm{MeB}(\mathbf{b})$ and $10 \mathrm{M} \mathrm{H}_{2} \mathrm{O}_{2}(\mathbf{c})$

anchors through carboxylic groups (Anselmi et al. 2012) and MeB is adsorbed physically (Chang et al. 2004).

Since Degussa P25 has more developed, but nonhydroxylated surface, it shows almost no difference in photocatalytic activity on sensitization with $\mathrm{H}_{2} \mathrm{O}_{2}$ and dyes. Slightly higher activity of MeB-sensitized Degussa 
Table 5 Average sizes $(\mu \mathrm{m})$ of microparticles formed during treatment of anatase (A) (method 1, samples 1-3) and $\mathrm{TiO}_{2}$ sol (method 2, samples 10-12) with dyes and $\mathrm{H}_{2} \mathrm{O}_{2}$

\begin{tabular}{lcc}
\hline Sample & After 1-2 min & After 15 min \\
\hline $\mathbf{1}(\mathrm{A}-\mathrm{MeB})$ & $\sim 4$ & $\sim 40$ \\
$\mathbf{2}(\mathrm{A}-\mathrm{MeR})$ & $\sim 8$ & $\sim 8$ \\
$\mathbf{3}\left(\mathrm{A}-\mathrm{H}_{2} \mathrm{O}_{2}\right)$ & $\sim 2$ & $\sim 2$ \\
$\mathbf{1 0}(\mathrm{MeB}-\mathrm{TiO} 2)$ & $\sim 4$ & $\sim 10$ \\
$\mathbf{1 1}(\mathrm{MeR}-\mathrm{TiO} 2)$ & $\sim 6$ & $\sim 9$ \\
$\mathbf{1 2}\left(\mathrm{H}_{2} \mathrm{O}_{2}-\mathrm{TiO}_{2}\right)$ & $\sim 2$ & $\sim 1$ \\
\hline
\end{tabular}

P25 can be explained by good sorption of the dye on its surface. We can propose that lower photocatalytic activity for MeR-sensitized titania in all cases, excluding Hombikat UV 100, is caused by competition between sensitizer $(\mathrm{MeR})$ and substrate $(\mathrm{MeO})$ with similar structures for titania surface. Hombikat UV100 differs from other titania samples by significantly higher specific surface area. Therefore, Hombikat UV100 has enough working surface to level competition between MeR and $\mathrm{MeO}$.

Microphotos allow analyzing processes of formation of microparticles in the reaction mixtures on preparing samples by the two methods (Figs. 9, 10; Table 5). The average size of anatase (A) microparticles dispersed in water is $\sim 3 \mu \mathrm{m}$; they form elongated aggregates $(\sim 15 \mu \mathrm{m})$. When using method 1 , microparticle size increases on treatment with organic dyes and decreases on treatment with $\mathrm{H}_{2} \mathrm{O}_{2}$. Chemical sorption of MeR and $\mathrm{H}_{2} \mathrm{O}_{2}$ on titania causes destruction of aggregates, while physical sorption of $\mathrm{MeB}$ initiates further aggregation. Treatment of titania sol with dyes and $\mathrm{H}_{2} \mathrm{O}_{2}$ along with a coagulant (method 2) produces microparticles united in growing aggregates. It is noteworthy than the use of $\mathrm{H}_{2} \mathrm{O}_{2}$ results in formation of smaller microparticles and needle-like aggregates with developed surface. Therefore, formation of peroxo chelate complexes with surface titanium atoms decreases the size of the particles and increases their photocatalytic activity.

To confirm the visible light photocatalytic properties of the best catalyst, $\mathrm{H}_{2} \mathrm{O}_{2}-\mathrm{TiO}_{2}$, we tested its photocatalytic activity in the reaction of degradation of molecules without absorbing visible light. The rate of destruction of salicylic acid with $\mathrm{H}_{2} \mathrm{O}_{2}-\mathrm{TiO}_{2}\left(k=0.017 \mathrm{~min}^{-1}\right)$ was higher than with the commercial visible light-responsive photocatalyst $\mathrm{TiO}_{2}(\mathrm{Mn})$ Aldrich (Obolenskaya et al. 2013) $\left(k=0.008 \mathrm{~min}^{-1}\right)$ (Fig. 11). Salicylic acid decomposes in $2 \mathrm{~h}$. In comparison, films of titanium oxide prepared with the use titanium peroxide (air dried and further heated at $400{ }^{\circ} \mathrm{C}$ ) were found to decompose salicylic acid under UV light in $4 \mathrm{~h}$ (Sonawane et al. 2003). Ma et al. (2012) found that $1.0 \% \mathrm{Eu} / \mathrm{N}-\mathrm{TiO}_{2}$ catalyst showed photocatalytic performance with $k$ of $0.0064 \mathrm{~min}^{-1}$ and the degradation of $88 \%$ salicylic acid in $5 \mathrm{~h}$; Liu et al. (2012) achieved $72.62 \%$ degradation of

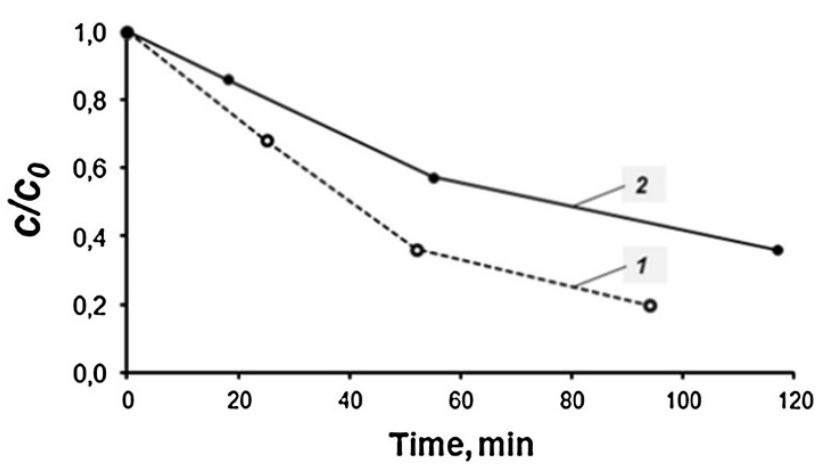

Fig. 11 Degree of destruction of salicylic acid under visible light in the presence of $\mathrm{H}_{2} \mathrm{O}_{2}-\mathrm{TiO}_{2}(1)$ and $\mathrm{TiO}_{2}(\mathrm{Mn})$-Aldrich (2)

salicylic acid in 120 min of visible light irradiation with the use of B-doped $\mathrm{TiO}_{2}$.

\section{Conclusion}

Sensitization of $\mathrm{TiO}_{2}$ samples with the organic dyes and peroxo complexes is a promising tool in expanding the effective absorption wavelength of $\mathrm{TiO}_{2}$ from ultraviolet to visible region.

The reaction rate constant of the $\mathrm{MeO}$ degradation under visible light depends on the catalyst type, the sensitizer, and the sensitization method.

In this work, we used traditional method of cold impregnation (method 1$)$ and the new method of sensitizing titania during the process of its synthesizing (method 2).

The best results were obtained for peroxide-sensitized $\mathrm{TiO}_{2}\left(\mathrm{H}_{2} \mathrm{O}_{2}-\mathrm{TiO}_{2}\right.$, sample 12) prepared by method 2 . The active sites in this photocalyst are the colored titanium peroxocomplexes on the surface of titania nanoparticles.

Acknowledgments The authors acknowledge the Russian Foundation for Basic Research (project no. 13-03-00367) for supporting this work.

Open Access This article is distributed under the terms of the Creative Commons Attribution License which permits any use, distribution, and reproduction in any medium, provided the original author(s) and the source are credited.

\section{References}

Anselmi Ch, Mosconi E, Pastore M, Ronca E, De Angelis F (2012) Adsorption of organic dyes on $\mathrm{TiO}_{2}$ surfaces in dye-sensitized solar cells: interplay of theory and experiment. Phys Chem Chem Phys 14:15963-15974

Banerjee AN (2011) The design, fabrication, and photocatalytic utility of nanostructured semiconductors: focus on $\mathrm{TiO}_{2}$-based nanostructures. Nanotechnol Sci Appl 4:35-65 
Brown GT, Darwent JR (1984) Photo reduction of methylorange sensitized by colloidal titanium dioxide. J Chem Soc Faraday Trans 1(80):1631-1643

Carp O, Huisman CL, Reller A (2004) Photoinduced reactivity of titanium dioxide. Prog Solid State Chem 32:33-177

Chang H, Su C, Lo CH, Chen LC, Tsung TT, Jwo CS (2004) Photodecomposition and surface adsorption of methylene blue on $\mathrm{TiO}_{2}$ nanofluid prepared by ASNSS. Mater Trans 45:3334-3337

Colón G, Hidalgo MC, Navío JA (2001) Photocatalytic deactivation of commercial $\mathrm{TiO}_{2}$ samples during simultaneous photoreduction of $\mathrm{Cr}(\mathrm{VI})$ and photooxidation of salicylic acid. J Photochem Photobiol A Chem 138:79-85

Dadachov M (2006) Novel adsorbents and process of making and using same. US Pat. Appl. 0144793, 6 July 2006

Epling GA, Lin C (2002) Photo-assisted bleaching of dyes utilizing $\mathrm{TiO}_{2}$ and visible light. Chemosphere 46:561-570

Fujishima A, Rao TN (1998) Interfacial photochemistry: fundamentals and applications. Pure Appl Chem 70:2177-2187

$\mathrm{Ge} \mathrm{L}, \mathrm{Xu}$ M (2007) Fabrication and characterization of $\mathrm{TiO}_{2}$ photocatalytic thin film prepared from peroxo titanic acid sol. J Sol Gel Sci Technol 43:1-7

Hashimoto K, Irie $\mathrm{H}$, Fujishima A (2007) $\mathrm{TiO}_{2}$ photocatalysis: a historical overview and future prospects. AAPPS Bull $17: 8269-8285$

Houas A, Lachheb H, Ksibi M, Elaloui E, Guillard Ch, Herrmann J-M (2001) Photocatalytic degradation pathway of methylene blue in water. Appl Catal B Environ 31:145-157

Hussein FH, Alkhateeb AN (2007) Photo-oxidation of benzyl alcohol under natural weathering conditions. Desalination 209:350-355

Jiaguo Yu, Huogen Yu, Bei Ch, Zhou M, Zhao X (2006) Enhanced photocatalytic activity of $\mathrm{TiO}_{2}$ powder (P25) by hydrothermal treatment. J Mol Catal A Chem 253:112-118

Karuppuchamy S, Jeong JM (2006) Synthesis of nano-particles of $\mathrm{TiO}_{2}$ by simple aqueous route. J Oleo Sci 55:263-266

Kubota LT, Gushikem Y, Mansanares AM, Vargas H (1995) Sorption of hydrogen peroxide by titanium(iv) oxide grafted on silica gel surface. J Coll Interface Sci 173:372-375

Liu X, Guo W, Ma J (2012) Hydrothermal preparation of B-doped $\mathrm{TiO}_{2}$ and photodegradation of salicylic acid under visible light. Adv Mater Res 557-559:1592-1595

Ma Yu, Zhang J, Tian B, Chen F, Bao Sh, Anpo M (2012) Synthesis of visible light-driven $\mathrm{Eu}, \mathrm{N}$ co-doped $\mathrm{TiO}_{2}$ and the mechanism of the degradation of salicylic acid. Res Chem Intermed 38:1947-1960
Obolenskaya LN, Kuz'micheva GM, Savinkina EV, Sadovskaya NV, Zhilkina AV, Prokudina NA, Chernyshev VV (2012a) Influence of the conditions of the sulfate method on the characteristics of nanosized anatase-type samples. Rus Chem Bull 61:2049-2055

Obolenskaya LN, Kuz'micheva GM, Savinkina EV, Prokudina NA, Chernyshev VV, Sadovskaya NV (2012b) Effect of sulfate synthesis conditions on characteristics of samples with the nanosized eta- $\mathrm{TiO}_{2}$ modification. Rus $\mathrm{J}$ Inorg Chem 57:1177-1181

Obolenskaya LN, Domoroshchina EN, Savinkina EV, Kuzmicheva GM (2013) Preparation, characterization and photocatalytic properties of nanosized anatase modified by manganese(IV). Fund Res 1-3:796-801

Pei D, Luan J (2012) Development of visible light-responsive sensitized photocatalysts. Int J Photoenergy 2012: ID 262831

Sauvé G, Cass ME, Coia G, Doig SJ, Lauermann I, Pomykal KE, Lewis NS (2000) Dye sensitization of nanocrystalline titanium dioxide with osmium and ruthenium polypyridyl complexes. J Phys Chem B 104:6821-6836

Simonsen ME, Jensen H, Li Zh, Søgaard EG (2008) Surface properties and photocatalytic activity of nanocrystalline titania films. J Photochem Photobiol A Chem 200:192-200

Sonawane RS, Hegde SG, Dongare MK (2003) Preparation of titanium(IV) oxide thin film. Mater Chem Phys 77:744-750

Varma RS, Baruwati B, Virkutyte J (2011) Doped titanium dioxide as a visible and sun light photocatalyst. US Pat. Appl. 0266136, 3 Nov 2011

Viswanathan B, Krishnamurthy KR (2012) Nitrogen incorporation in $\mathrm{TiO}_{2}$ : does it make a visible light photo-active material? Int $\mathbf{J}$ Photoenergy 2012:ID 269654

Zhang X, Veikko U, Mao J, Cai P, Peng T (2012) Visible-lightinduced photocatalytic hydrogen production over binuclear $\mathrm{Ru}^{\mathrm{II}}$ bipyridyl dye-sensitized $\mathrm{TiO}_{2}$ without noble metal loading. Chem Eur J 18:12103-12111

Zhou XT, Ji HB, Huang XJ (2012) Photocatalytic degradation of methyl orange over metalloporphyrins supported on $\mathrm{TiO}_{2}$ Degussa P25. Molecules 17:1149-1158

Zou J, Gao J, Wang Y (2009) Synthesis of highly active $\mathrm{H}_{2} \mathrm{O}_{2-}$ sensitized sulfated titania nanoparticles with a response to visible light. J Photochem Photobiol A Chem 202:128-135 